\title{
On Stability and Ice-Releasing Performance of Nanostructured Fluoro-Alkylsilane-Based Superhydrophobic Al alloy2024 Surfaces
}

\author{
Shahram Farhadi, Masoud Farzaneh \\ NSERC/Hydro-Quebec Industrial Chair and Canada Research Chair on Atmospheric Icing of Power Network \\ Equipment (CIGELE/INGIVRE) \\ Université du Québec à Chicoutimi, 555 University boulevard, Saguenay, PQ, Canada G7H 2B1 \\ shahram.farhadi@uqac.ca; masoud_farzaneh@uqac.ca
}

\author{
Stéphan Simard \\ Aluminium Assembling Group, Aluminium Technology Centre, Industrial Materials Institute, \\ National Research Council Canada (CNRC) \\ 501, boul. de l'Université Est, Saguenay, QC, Canada, G7H 8C3 \\ stephan.simard@imi.cnrc-nrc.gc.ca
}

\begin{abstract}
Atmospheric icing occurs when surface of exposed structures come into contact with supercooled water droplets and/or snow particles. Ice and wet-snow adhesion and excessive accumulation on exposed structures and equipment is well known as a source of numerous types of failures and malfunctions in power transmission lines, aircrafts, boats etc. in many cold-climate regions. Hydro-/superhydrophobic coatings have been developed over the past few decades as a passive technique to reduce or prevent ice accumulation on outdoor structures. In this study, superhydrophobic Al alloy (AA2024) substrates with static water contact angle values of (CA) $>163^{\circ}$ and water contact angle hysteresis values of $(\mathrm{CAH}) \leq 5^{\circ}$ were prepared by etching aluminium alloy substrate in hot water followed by further surface hydrophobization with 1H,1H,2H,2H-perfluorodecyltriethoxysilane (FAS-17) using wet-chemistry technique. The prepared coated Al alloy samples showed good superhydrophobic and self-cleaning properties. Systematic study of both water-and ice-repellent behaviour of such organic coatings terminated by alkyl groups and expected to reduce ice adhesion, were then conducted. The stability tests of the coated surfaces with $C A>150^{\circ}$ in water resulted in a gradual loss of their superhydrophobic properties after $\sim 1280$ $h$ of immersion. Artificially created glaze ice, similar to the naturally accreted one, was deposited on the nanostructured surfaces by spraying supercooled water micro-droplets with the average size of $\sim 80 \mu \mathrm{m}$ in a wind tunnel at subzero temperature $\left(-10^{\circ} \mathrm{C}\right)$ and a wind speed of $11 \mathrm{~m} / \mathrm{s}$. The ice adhesion strength was evaluated by spinning the samples in a
\end{abstract}

centrifuge at constantly increasing speed until ice delaminating occurred. While the uncoated as-received Al alloy samples were found to have an average ice detachment shear stress of $\sim 445 \pm 20 \mathrm{kPa}$, their counterparts coated with a thin layer of FAS-17 showed a lower value of $\sim 65 \mathrm{kPa}$. This reduction is attributed to the presence of engineered micro/nano-hierarchical surface asperities and to applying low surface energy layers on the sample surfaces. However, the results show that the anti-icing properties of the tested samples deteriorate over time.

Keywords: Sperhydrophobic Properties, Nanostructured Al Surfaces, Fluoro-Alkylsilane-Based Layers, Self-cleaning, SelfAssembly, Ice Repellency, Wetting Hysteresis and Durability

(C) Copyright 2012 Authors - This is an Open Access article published under the Creative Commons Attribution License terms (http://creativecommons.org/licenses/by/2.0). Unrestricted use, distribution, and reproduction in any medium are permitted, provided the original work is properly cited.

\section{Introduction}

Atmospheric icing occurs when the surfaces of exposed structures come into contact with supercooled water droplets or snow particles. Ice and wet-snow adhesion to exposed surfaces is the source of several types of malfunctions in power transmission lines, aircrafts, boats etc. in cold climate regions (Farzaneh, 2008). Prevention of icing requires 
reducing its adhesive strength. Therefore, various de-icing and anti-icing techniques were developed over the last decades. By now, certain coatings have been developed to reduce ice adhesion resulting in lower ice or snow accumulation (Saito et al., 1997, Kulinich and Farzaneh, 2004, 2005, 2009, Menini and Farzaneh, 2009, Arianpour et al., 2013). The ideal solution would be applying a durable, easy to process, and inexpensive material which would reduce adhesion to such an extent that ice would fall off under the pull of gravity, e.g. alkyl-terminated coatings such as alkylsilane and fluoroalkylsilane-based layers (Petrenko and Peng, 2003, Kulinich and Farzaneh, 2004, Farzaneh, 2010). Good correlation between hydrophobicity of surfaces and their ice-repellent behaviour was previously reported by several groups (Saito et al., 1997, Petrenko and Peng, 2003, Farhadi et al., 2011, Arianpour et al., 2013). Superhydrophobic surfaces, exhibiting static water contact angle (CA) $>150^{\circ}$ and low values of CA hysteresis (CAH), have recently attracted significant attention. It is well known that the key factors underlying superhydrophobicity are chemical composition along with micro-/nano-hierarchical texture (Kulinich and Farzaneh, 2004, Quéré, 2005, Crick et al., 2010, Yao et al., 2010, Farhadi et al., 2011). The ability of superhydrophobic surfaces to reduce ice or snow accumulation was first tested by Saito et al., 1997. It has been also demonstrated that superhydrophobicity can improve self-cleaning and anti-corrosive properties of $\mathrm{Al}$ alloys (Menini and Farzaneh, 2009, Guo et al., 2005, Shaojun et al, 2011). Arianpour et al., 2010, reported delayed water freezing on rough superhydrophobic surfaces. Various techniques have been already reported for producing superhydrophobic surfaces (Meng et al., 2008, Menini and Farzaneh, 2009, Mingjie et al, 2010, Shaojun et al, 2011). Anyhow, the systematic study of their hydrophobic and icerepellent properties has not been reported thus far. As concerns the methods used to evaluate ice-solid adhesion (Andrews et al., 1983, Croutch and Hartley, 1992, Somlo et al., 2001), in most of the research works, water was artificially frozen on top of the samples tested under unrealistic icing conditions. Therefore, testing adhesion of glaze ice prepared by spraying supercooled water droplets is expected to give more reliable results (Kulinich and Farzaneh, 2009, Menini and Farzaneh, 2009, Farhadi et al, 2011, Arianpour et al., 2013). It was clearly shown that contact angle hysteresis (CAH) along with the CA governs the ice-solid adhesion strength.

In the present study, a simple and easy-to-use approach to elaborate superhydrophobic Al alloy surface will be presented. More precisely, organic coatings terminated with alkyl groups were prepared as potential ice/snow-repellent layers on AA2024 via etching in hot water for a certain time followed by a one-layer surface modification. The prepared samples with etching time of more than three hours showed enhanced superhydrophobicity with $\mathrm{CA}>163^{\circ}$ and $\mathrm{CAH} \leq 5^{\circ}$ and demonstrating good self-cleaning properties, water droplets rolling off the surface easily. These nanostructured surfaces were characterized and tested with the proper procedures, and both the coating stability in water and icerepellent performance over time were carefully studied. Furthermore, it was found that the surface elaboration method presented in this research work, is simple, fast, easyto-use and inexpensive and would be of interest for industrial or large-scale manufacturing.

\section{Experimental procedure \\ 2. 1. Sample Preparation}

All the coated samples tested in this work were prepared on AA2024 substrates, whose chemical composition is composed of $\mathrm{Si}$ of $0.50 \mathrm{wt} . \%$, Fe of $0.50 \mathrm{wt} . \%$, Cu of 3.8-4.9 wt.\%, Mn of $0.30-1.0$ wt.\%, $\mathrm{Zn}$ of 0.25 wt.\%, Mg of $1.2-1.8$ wt.\%, other impurity of 0.15 wt.\%, and the remaining element Al (Spadaro et al., 2008, Yina et al., 2011). As it is evident, this alloy has a high $\mathrm{Cu}$ content, typically between 3.8-4.9\% (wt. \%) (Palominoa et al., 2007). The as-received $\mathrm{Al}$ substrates, $2 \mathrm{~mm}$ thick, were cleaned and degreased ultrasonically in organic solvents (methanol, acetone and Turco Redoline 53D alkaline solution, each for $8 \mathrm{~min}$. The cleaned samples were blown-dried in $\mathrm{N}_{2}$ gas flow and then etched in hot water $\left(95^{\circ} \mathrm{C}\right)$ for different times (Table 1 ). Finally, they were coated with FAS-17 solution for $3 \mathrm{~h}$ to decrease the surface energy. Upon coating and prior to tests, the treated samples were removed from the solution, rinsed with copious amounts of methanol and blown-dried with $\mathrm{N}_{2}$ followed by heat-treatment at $80{ }^{\circ} \mathrm{C}$ for $2 \mathrm{~h}$ to remove any volatile components or residual solvents. While the smaller samples $(1.5 \mathrm{~cm} \times 1.5 \mathrm{~cm})$ were used to test the stability of the coatings in water, the larger ones $(3.2 \mathrm{~cm} \times 5.2 \mathrm{~cm})$ were further used to evaluate their ice-repellent performance. Figure 1 is a schematic presentation of the sample preparation procedure.

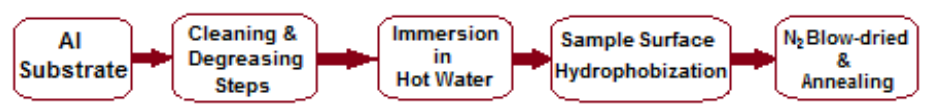

Fig. 1. Schematic presentation of sample preparation process.

\section{2. Coated sample analyses}

The sample stability in water over time was characterized by means of contact angle measurements on samples immersed in deionized water for different periods of time. The wetting characteristics reported in Table 1 were obtained following the standard sessile drop method on a CA goniometer (DSA100 from Krüss) with controllable volume $(4 \mu$ l) of water drops. Deionized water with water conductivity of $\sim 0.32 \mu \mathrm{S} / \mathrm{cm}$ at $\sim 19{ }^{\circ} \mathrm{C}$ was used in the experimental process. These measurements were performed with the Young-Laplace method (Kulinich and Farzaneh, 2005, Menini and Farzaneh, 2009, Farhadi et al, 2011). Surface topographies were analyzed with scanning electron microscopy (SEM, Hitachi FEGSEM-SU 70) in high-vacuum 
mode and atomic force microscopy (AFM, Escope from Veeco). X-ray photoelectron spectroscopy (XPS) was performed with a Quantum-2000 instrument from PHI. The ice tested was of glaze type of up to $\sim 1 \mathrm{~cm}$ thick and $\sim 5 \mathrm{gr}$ weight over the $\sim 3.2 \times 3.0 \mathrm{~cm}^{2}$ area and prepared by spraying supercooled microdroplets of water (average size of $\sim 80 \mu \mathrm{m}$ ) in a wind tunnel at subzero temperature $\left(-10{ }^{\circ} \mathrm{C}\right)$ and a wind speed of $11 \mathrm{~m} / \mathrm{s}$, with a water feed rate of $2.5 \mathrm{~g} / \mathrm{m}^{3}$ simulating "freezing rain". The requisite time in the tunnel for preparing glaze ice of up to $\sim 1 \mathrm{~cm}$ thick was about 8 to 10 min. Prior to icing, all samples were placed in the tunnel for approximately $10 \mathrm{~min}$ to cool down. Iced samples were then spun in the centrifuge at constantly increasing speed. The shear stress was calculated taking into account the mass and area of the ice detached and by precisely detecting the rotational speed of the sample at the moment of ice failure (adhesive). The procedures of ice preparation and ice adhesion evaluation have been described in greater detail elsewhere (Kulinich and Farzaneh, 2009, Farhadi et al, 2011, Arianpour et al., 2013).

\section{Results and Discussion}

\subsection{CA and CAH of Coated Samples}

Aluminium alloy is a hydrophilic material with native oxidized top layer showing water contact angle and surface energy of $\sim 40 \pm 3^{\circ}$ and $57.73 \pm 1.11(\mathrm{mN} / \mathrm{m})$, respectively. After etching in hot water, the bare aluminium alloy surface showed water contact angle and surface energy of $\sim 21 \pm 4^{0}$ and $67.58 \pm 0.82(\mathrm{mN} / \mathrm{m})$, respectively. However, after modifying the etched Al surfaces with FAS-17, the asprepared superhydrophobic surfaces of aluminium alloy showed water $\mathrm{CA}>150^{\circ}$, as shown in Fig. 2.

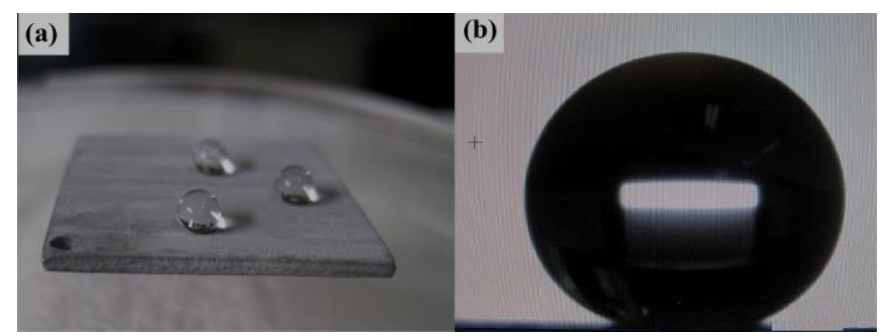

Fig. 2. (a) Image of water droplets on different spots of as-prepared $\mathrm{Al}$ alloy surface. (b) Profile of a water droplet on the $\mathrm{Al}$ alloy surface $\left(\mathrm{CA}>150^{\circ}\right)$.

The water droplets did not come to rest and easily rolled off from the surface even when the surface was on a level table $\left(<2^{\circ}\right)$, which made it very difficult to measure the CAs values. As mentioned earlier, the samples wetting characteristics, listed in Table 1, were calculated according to the Young-Laplace method, considered as the most theoretically accurate one (Kulinich and Farzaneh, 2009).
Table 1. Preparation and properties of analysed samples (hot water temperature of $95^{\circ} \mathrm{C}$ )

\begin{tabular}{|c|c|c|c|c|c|c|}
\hline స్త్ర & 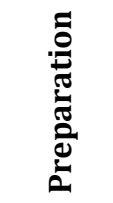 & 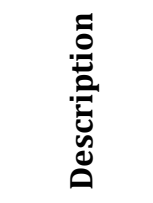 & 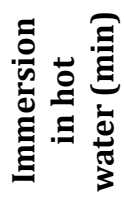 & 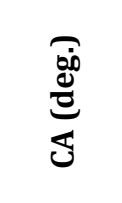 & $\underbrace{\overparen{8}}$ & 司 \\
\hline A & $\begin{array}{c}\text { Dip- } \\
\text { coating }\end{array}$ & $\begin{array}{l}\text { Flat AI/ } \\
\text { FAS-17 }\end{array}$ & 0 & $\begin{array}{c}108.2 \pm \\
1\end{array}$ & - & 100 \\
\hline B & $\begin{array}{c}\text { Dip- } \\
\text { coating }\end{array}$ & $\begin{array}{c}\text { Etched AI- } \\
\text { FAS } 17\end{array}$ & 180 & $\begin{array}{c}148.3 \pm \\
0.9\end{array}$ & $\begin{array}{l}9 \pm \\
1.1\end{array}$ & 21.6 \\
\hline C & $\begin{array}{c}\text { Dip- } \\
\text { coating }\end{array}$ & $\begin{array}{c}\text { Etched AI- } \\
\text { FAS } 17\end{array}$ & 210 & $\begin{array}{c}156.1 \pm \\
0.8\end{array}$ & $\begin{array}{c}5.7 \pm \\
0.5\end{array}$ & 12.4 \\
\hline D & $\begin{array}{c}\text { Dip- } \\
\text { coating }\end{array}$ & $\begin{array}{c}\text { Etched AI- } \\
\text { FAS } 17\end{array}$ & 240 & $\begin{array}{c}165.6 \pm \\
0.5\end{array}$ & $\begin{array}{c}4.7 \pm \\
0.7\end{array}$ & 4.6 \\
\hline $\mathbf{E}$ & $\begin{array}{c}\text { Dip- } \\
\text { coating }\end{array}$ & $\begin{array}{c}\text { Etched AI- } \\
\text { FAS } 17\end{array}$ & 300 & $\begin{array}{c}163 \pm \\
0.7\end{array}$ & $\begin{array}{l}5 \pm \\
0.7\end{array}$ & 6.3 \\
\hline
\end{tabular}

The XPS signals of C, O, Si and F, as shown in Fig. 3, are observed on the as-prepared superhydrophobic Al alloy surfaces, demonstrating well covered Al surfaces with low surface energy coating of FAS-17 molecules which significantly reduced the energies of the surfaces.

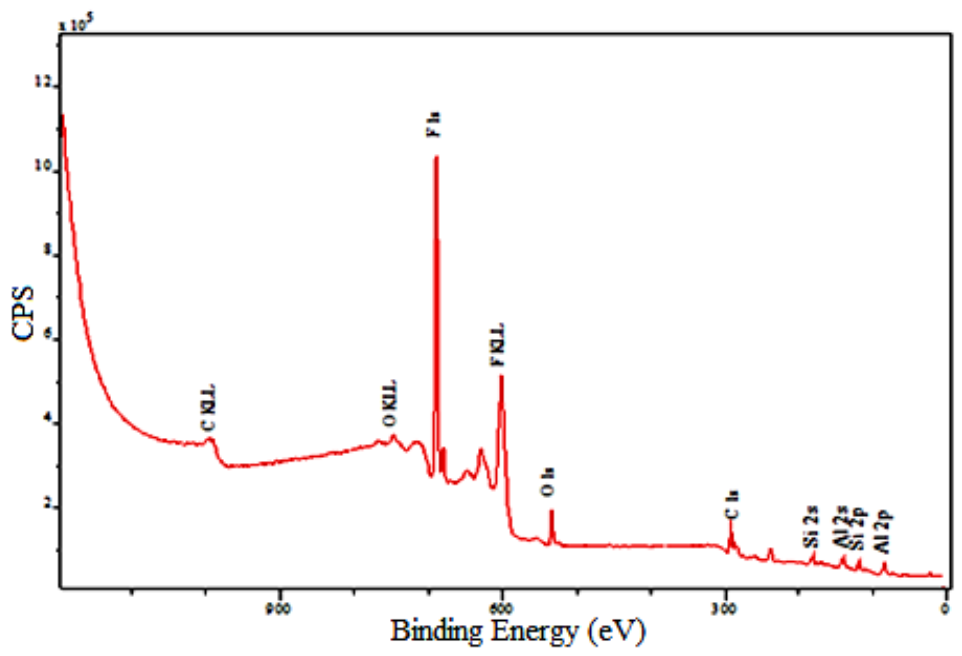

Fig. 3. XPS spectrum of FAS-17 layer on as-prepared superhydrophobic AA surface (sample D).

Figure 4 shows CA and CAH values of prepared samples with different etching time in hot water as well as the coated flat AA surface. While the measured contact angle on the flat Al sample coated with FAS-17 (sample A) is $\sim 108.2^{\circ}$ (and surface energy of $18.25 \pm 1.17(\mathrm{mN} / \mathrm{m}))$, it can be seen that the last two samples (D and E) show good superhydrophobic properties as $\mathrm{CA}>163^{\circ}$ and $\mathrm{CAH} \leq 5^{\circ}$. However, sample $\mathrm{C}$ also shows superhydrophobic properties as its $\mathrm{CA}$ and $\mathrm{CAH}$ values are $\sim 156^{\circ}$ and $\sim 5.7^{\circ}$, respectively. This implies that water droplets will rest on top of the rough asperities of solid-air 
composite surfaces (Cassie-Baxter wetting regime). In this regime, CA can be expressed as follows:

$$
\operatorname{Cos} \theta^{*}=f(1+\operatorname{Cos} \theta)-1
$$

where $\theta^{*}$ and $\theta$ are the CA of the rough and flat surfaces, respectively, with the same surface chemistry, and $f$ is the area fraction of the solid surface that contacts water (Quéré, 2005, Crick et al., 2010, Furuta et al., 2010, Spori, et al., 2010). The Cassie-Baxter model assumes that a droplet is suspended on the rough asperities and allows air trapping between them on a surface underneath the droplet. This air is a key factor for superhydrophobic behaviour, so that the $f$ values on real superhydrophobic surfaces are small (Quéré, 2005, Crick et al., 2010, Furuta et al., 2010). The maximum CA value and minimum $\mathrm{CAH}$ is for sample $\mathrm{D}$ with $\mathrm{CA}$ and $\mathrm{CAH}$ values of $165.6^{\circ}$ and $4.7^{\circ}$, respectively. Considering the obtained CA values, f can be calculated (Table 1), demonstrating a large amount of trapped air beneath the water droplets. As reported previously (Kulinich and Farzaneh, 2009), this results in a small water-solid contact areas on such surfaces.

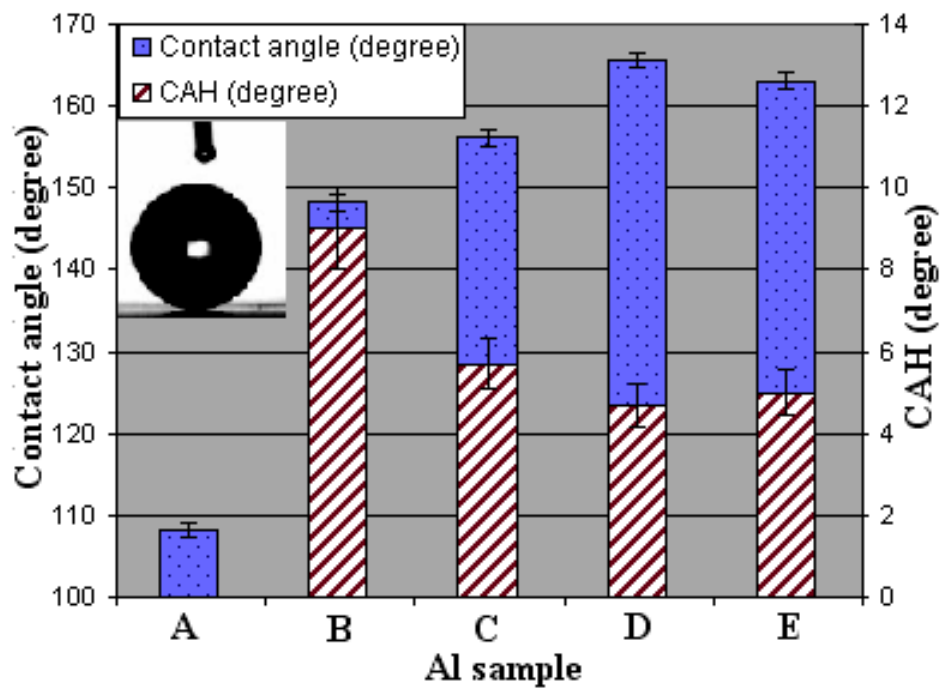

Fig. 4. Contact angle and contact angle hysteresis values of prepared samples with different etching time in hot water.

By decreasing the contact area between a water droplet and the surface, the three phase contact line at the solid/liquid interface is decreased. A slight increase in CAH values with increasing the etching time can be attributed to further micro-rods piling on the sample surface, leading a decrease in water rolling off the surface. However, all superhydrophobic samples demonstrated good self-cleaning property as the soil mesh was easily carried away by water droplet passing by as shown in Fig.5. Figure 6 shows scanning electron micrographs (SEM) of sample D at different magnifications while showing rough samples at micro/nanoscale, with the root-mean-square roughness $\left(R_{r m s}\right)$ measured automatically using atomic force microscopy for $\leq 320 \mathrm{~nm}$.
The root-mean-square roughness $\left(\mathrm{R}_{\mathrm{rms}}\right)$ values measured for as-received and mirror-polished $\mathrm{Al}$ samples were 38 and 10 $\mathrm{nm}$, respectively.

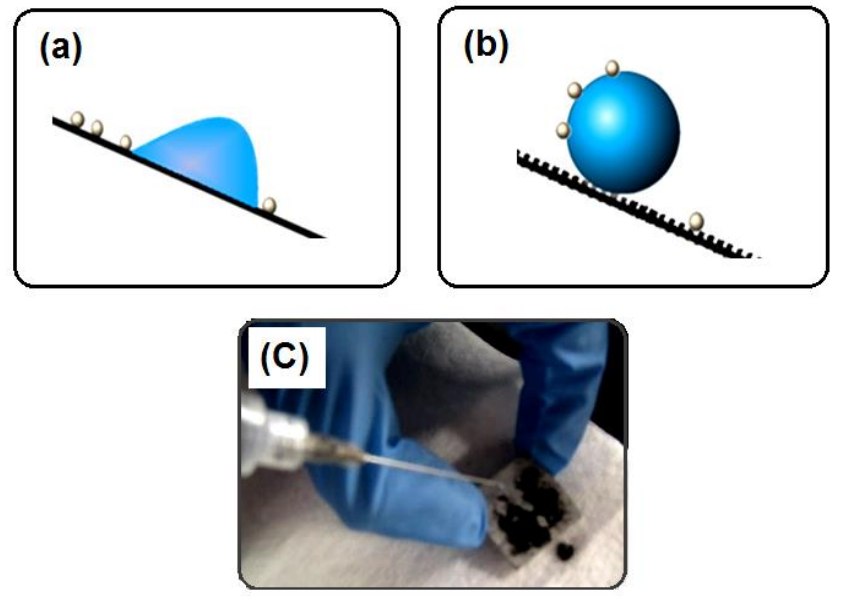

Fig. 5. Schematic presentation of (a) a normal surface, (b) a surface with self-cleaning property and (c) as-prepared superhydrophobic Al samples after a water droplet passing by on a soil mesh.

Since air was expected to be entrapped into such structures during wetting, the Cassie-Baxter wetting mode was expected for these samples with high surface roughness and low-energy top layers (Miwa et al., 2000, Kulinich and Farzaneh, 2004). Also, the high CA and low CAH values observed let us assume good surface coverage with FAS-17 molecules. The water-solid contact area on these samples was expected to be small, which is consistent with the small CAH values $\left(\sim 4-6^{\circ}\right)$ and high CA values $\left(\sim 156.1-165.6^{\circ}\right)$, which are characteristic of superhydrophobic surfaces. As it is evident, different micro- and/or nano-surface asperities can be found on etched $\mathrm{Al}$ alloy surfaces including nanopieces, cavity or holes covered by nano-pieces and microrods. The Al sample is uniformly covered by nano-pieces with $\sim 500 \mathrm{~nm}$ wide. Several micro-rods can be observed on the samples while scattered all over.
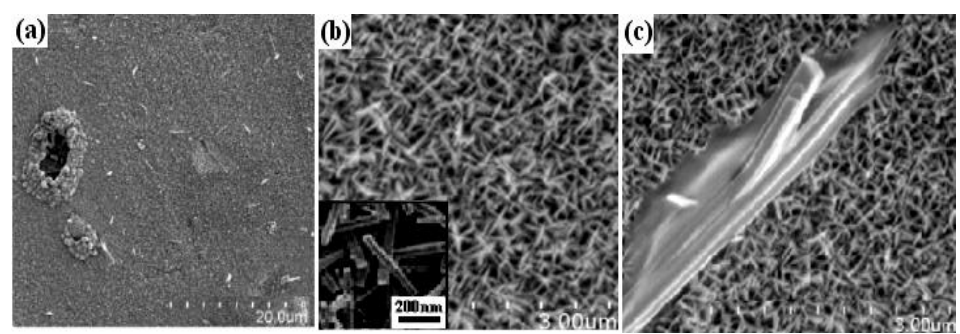

Fig. 6. (a) SEM images of etched superhydrophobic AA2024 sample used in this study (sample D), (b) nano-pieces and (c) micro-rods. The inset image in (b) stands for high magnification of nano-pieces.

Figure 7 schematically illustrates the Cassie-Baxter model, where a large amount of air is entrapped in the surface 
irregularities on a rough surface, leading to superhydrophobic properties.

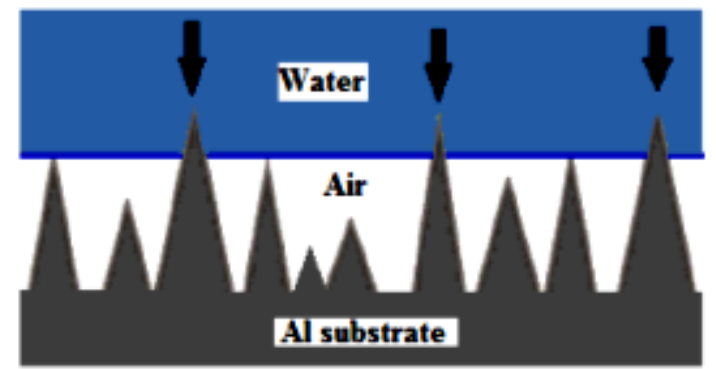

Fig. 7. Schematic presentation of the Cassie-Baxter wetting model for a superhydrophobic surface. Air is entrapped underneath water drops on the surface.

From the SEM micrographs, all etched treated samples have more or less similar morphology and are uniformly covered with nano-pieces. However, the total quantity of produced micro-rods increased while immersion time in hot water was increased. It is well known that by immersing $\mathrm{Al}$ samples in hot water, the samples will react with water and that $\mathrm{Al}(\mathrm{OH})_{3}$ will be produced while releasing $\mathrm{H}_{2}$ gas. Therefore, the following reactions ( 1 and 2 ) can be considered to happen:

$$
\mathrm{Al}+3 \mathrm{H}_{2} \mathrm{O} \rightarrow \mathrm{Al}(\mathrm{OH})_{3}+3 / 2 \mathrm{H}_{2}
$$

To be followed by:

$$
2 \mathrm{Al}(\mathrm{OH})_{3} \rightarrow \mathrm{Al}_{2} \mathrm{O}_{3}+3 \mathrm{H}_{2} \mathrm{O}
$$

The formation of nano-pieces is probably due to the dissimilarity of chemical reaction kinetics between water and Al crystal faces. Faster reaction in one dimension results in formation of surface nano-pieces (Guo et al., 2005, Mingjie et al. 2010). The observed cavities coated with nano-pieces are probably due to inherent cavities during Al manufacturing.

\subsection{Coating Stability in Water}

Figure 8 presents CA values as a function of immersion time in water for prepared nanostructured samples (samples $D$ and E). Both samples demonstrate initial values of $\mathrm{CA}>163^{\circ}$, indicating well-coated nano-structured superhydrophobic surfaces. However, both coatings studied were found to slowly lose their hydrophobic properties after $\sim 1280$-h of immersion in water, associated with a decrease of their CA values. This tendency to lose surface hydrophobic properties is most likely due to the rupture of the $\mathrm{Si}-\mathrm{O}-\mathrm{Al}$ bond between FAS-17 molecules and the surface of etched $\mathrm{Al}$ caused by hydrolysis of these bonds. It is reasonable to say that after subjecting the $\mathrm{Al}$ surfaces to a wet environment, the FAS-17 layer undergoes some degree of degradation (Frignani et al. 2006). As a result, some alkylsilane molecules were removed from the surface, resulting in a decrease of its hydrophobic properties.

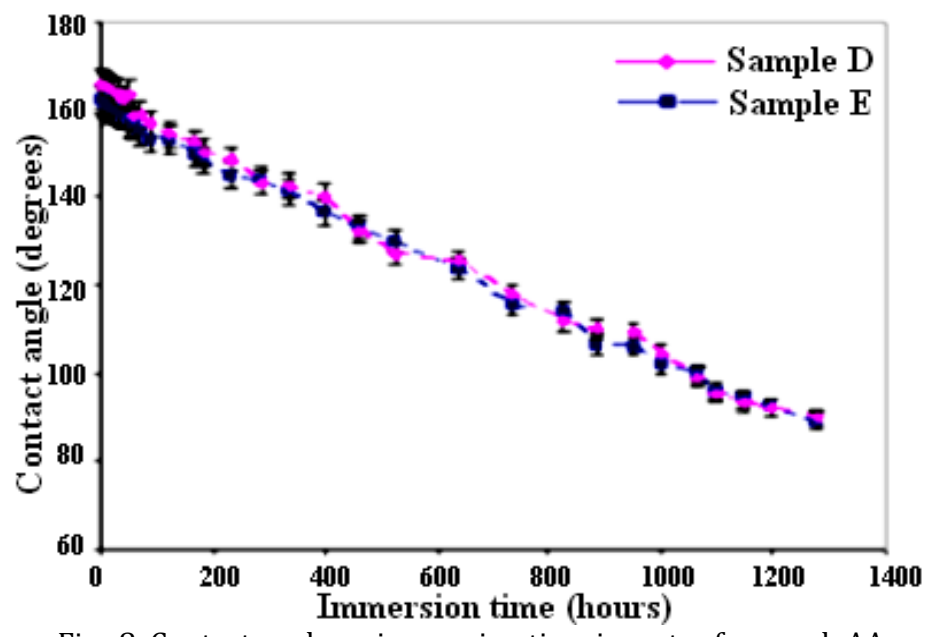

Fig. 8. Contact angle vs. immersion time in water for rough AA samples coated with FAS-17.

\subsection{Evaluation of Ice-Repellent Performance}

As natural icing events occur under more dynamic conditions than those previously applying for testing ice adhesion on materials (Somlo and Gupta, 2001, Petrenko and Peng, 2003, Sarkar and Farzaneh, 2009), this implies that the dynamic hydrophobicity of surfaces may play a role. This is believed to be even more important for rough nanostructured superhydrophobic surfaces. The glaze ice used to evaluate the ice repellent performance of the samples was prepared in a wind tunnel by spraying water micro-droplets with an average size of $\sim 80 \mu \mathrm{m}$ at subzero temperature $\left(-10^{\circ} \mathrm{C}\right)$ and a wind speed of $11 \mathrm{~m} / \mathrm{s}$ with a water feed rate of $2.5 \mathrm{~g} / \mathrm{m}^{3}$, that is, under conditions very close to outdoor ice accretion during "freezing rain" (Kulinich et al. 2011, Arianpour et al., 2013). The procedure to evaluate ice adhesion strength, measured as the shear stress of ice detachment, was previously reported in greater detail elsewhere (Kulinich and Farzaneh, 2009, Menini and Farzaneh, 2009). Each sample studied was subjected to 12 successive icing/de-icing events and thus, ice adhesion strength to each coating was analyzed as a function of the number of icing/de-icing cycles. Due to the very high mobility of water (described with low $\mathrm{CAH}$ ), the accretion of ice from "freezing rain" is delayed on such surfaces (Adam et al. 2010, Farhadi et al. 2011, Arianpour et al., 2013) which makes them very attractive as anti-ice materials. Figure 9 illustrates the shear stress of ice detachment from the samples as a function of the number of icing/de-icing cycles. All nano-structured superhydrophobic surfaces demonstrated noticeably close initial values of shear stress required to detach the ice, implying similar ice adhesion strength values. While uncoated as-received Al samples showed average ice detachment shear stress values of $\sim 445 \pm 20 \mathrm{kPa}$, their counterparts coated with FAS-17 
showed reduced values of $\sim 65 \mathrm{kPa}$. In agreement with the previous studies on low-CAH superhydrophobic surfaces (Kulinich and Farzaneh, 2009), the initial values of shear stress of ice detachment on the as-prepared samples were $\sim 7$ times lower than those on as-received Al standard, which is consistent with the above mentioned Cassie-Baxter wetting regime, as shown in Fig.7.

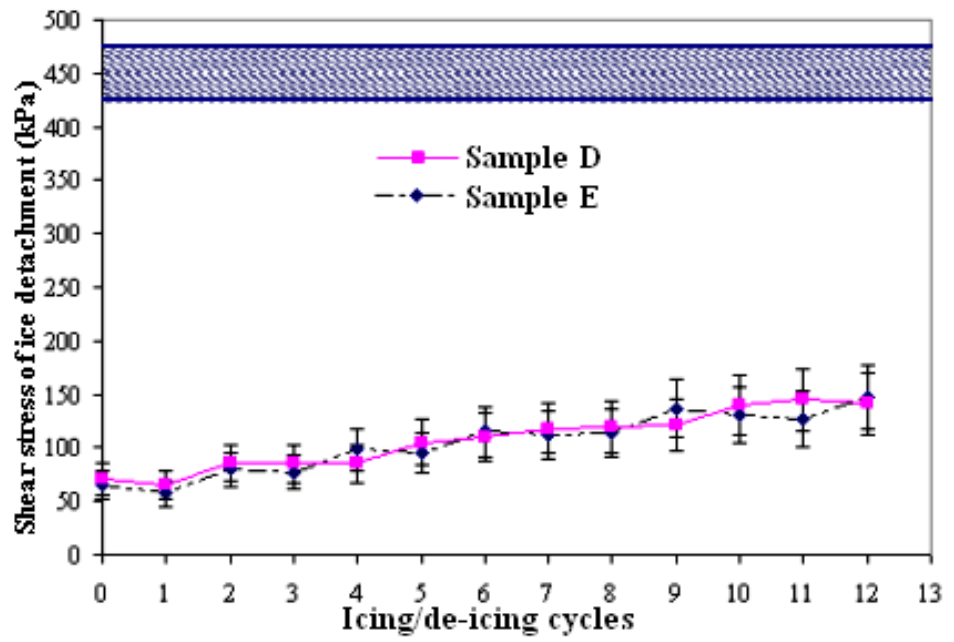

Fig. 9. Shear stress of ice detachment vs. icing/de-icing cycles for coated Al surfaces with FAS-17. The horizontal bar at $\sim 445 \pm 20 \mathrm{kPa}$ indicates value obtained on as-received $\mathrm{Al}$.

This reduction is attributed to the presence of engineered micro-/nano-hierarchical surface structures and low surface energy layers on the samples. However, the ice releasing performance of the samples gradually changed after several icing/de-icing cycles. All superhydrophobic samples demonstrated increase of ice adhesion strength if compared to the as-prepared surfaces. The observed increase in ice adhesion strength values is believed to be associated with a larger ice-solid contact area on these nano-structured surfaces after several icing/de-icing cycles (Kulinich and Farzaneh, 2009, Farhadi et al., 2011, Arianpour et al., 2013). As shown, after 12 icing/de-icing cycles, the samples demonstrated slight increase of ice adhesion strength which is believed to be associated with both a decay of the FAS-17 layers on the samples and a larger ice-solid contact area on the nanostructured surfaces after several icing/de-icing events. These samples seemed to be resistant to damage during icing/de-icing due to their more rigid asperities, made of $\mathrm{Al}_{\mathrm{x}} \mathrm{O}_{\mathrm{y}}$ or $\mathrm{Al}$ hydroxide. In other word, these samples showed remarkably lower deterioration rates and consequently, higher abrasive resistance during the icing/deicing cycles than those whose rough structures is based on practically loose nanoparticle-based samples prepared in our previous research work (Farhadi et al., 2011). This is expected due to different mechanical properties on which the samples prepared in this study had much firmer and stronger surface asperities. In parallel, contact angle and contact angle hysteresis values were also measured between icing/de-icing experiments. The water-repellent performance of both samples over time and after several icing/de-icing cycles was studied to better understanding of observed results. Figure 10 demonstrates how both contact angle and contact angle hysteresis values of samples $\mathrm{D}$ and $\mathrm{E}$ evolved as it was repeatedly subjected to icing/de-icing. It is evident from figure 10 that the water-repellent properties of both samples gradually deteriorated over time, which is seen as decreasing the contact angle values and increasing the wetting hysteresis (contact angle hysteresis, CAH) as they were randomly measured between icing/de-icing tests.
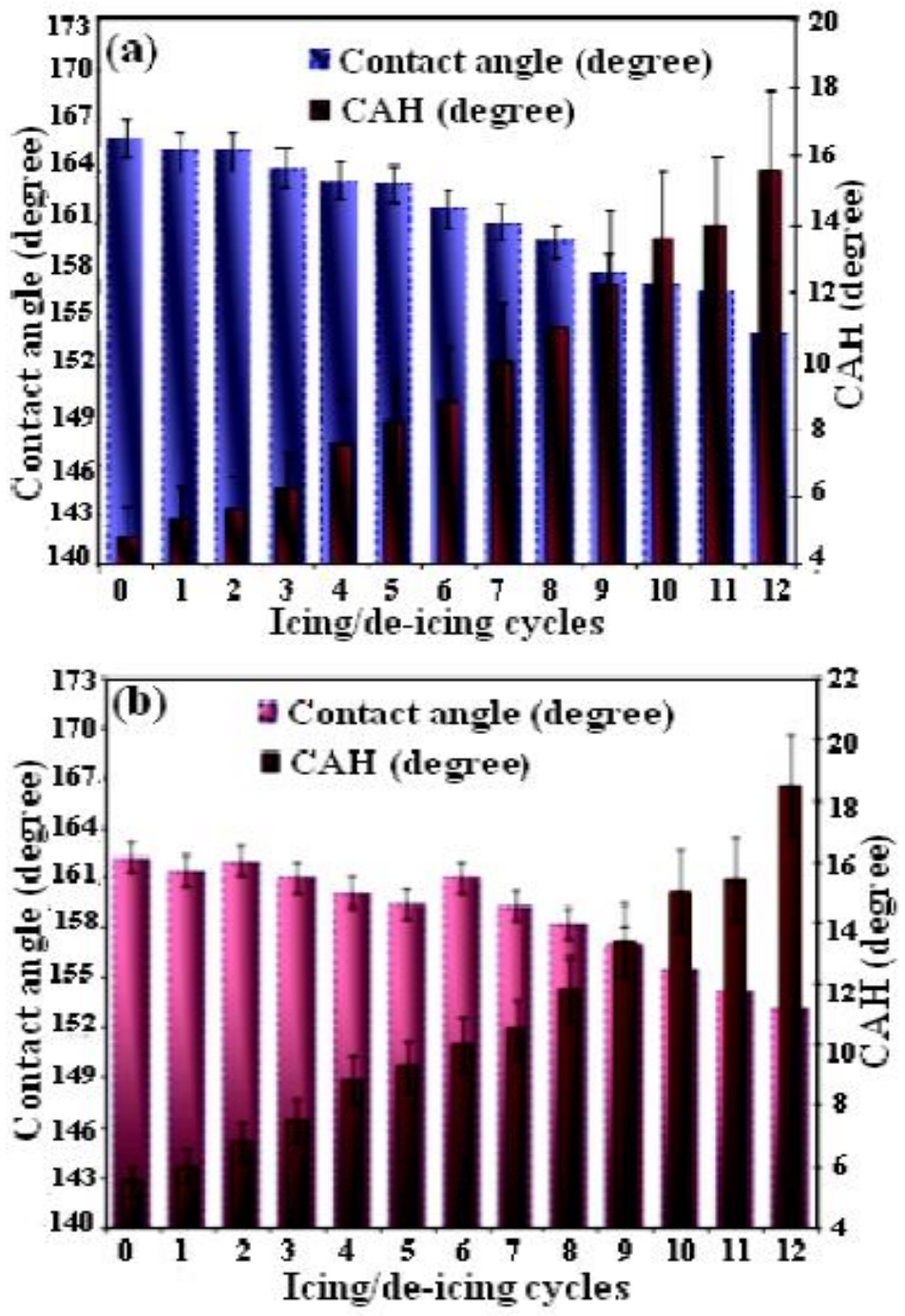

Fig. 10. CA and CAH values vs. icing/de-icing cycles for Al surfaces coated with FAS-17: (a) sample D and (b) sample E.

It is possible that by increasing the number of icing/deicing more and more, the sample will finally demonstrate lower values of contact angle, thus not being superhydrophobic anymore. It is reasonable to assume that a bit deteriorated water repellency, the increased ice adhesion 
strength and the decrease in surface roughness due to the icing/de-icing cycles can be related to a gradual damage of the rough structures of the sample surfaces. As the surface roughness of the samples decreased, consequently, partial switch of the wetting regime from a pure Cassie (low contact angle hysteresis and high contact angle values) to a mixed Wenzel-Cassie regime was expected on such surfaces, which had to cause the observed gradual increase in ice adhesion strength (Kulinich and Farzaneh, 2009, Kulinich et al. 2011, Farhadi et al., 2011, Arianpour et al., 2013).

\section{Conclusions}

In this study, a simple method to elaborate fluoro-alkylterminated nanostructured superhydrophobic surfaces was provided by depositing a layer of FAS-17 on etched AA2024 surfaces in hot water, which showed good superhydrophobic and self-cleaning properties. This process is easy to control and time saving. The stability of such surfaces in water was tested by means of contact angle measurements, showing a gradual loss of their superhydrophobicity after $\sim 1280$-h immersion in deionized water, this being associated with a decrease and increase of water $\mathrm{CA}$ and $\mathrm{CAH}$, respectively. Ice repellent performance of prepared nano-structured superhydrophobic coatings was evaluated after several icing/de-icing cycles and the results were compared to those on uncoated $\mathrm{Al}$ as a reference. The ice adhesion strength results illustrated that the anti-ice performance of the robust surface prepared by etching $\mathrm{Al}$ alloy substrates gradually deteriorated. More precisely, their ice-releasing performance gradually degraded during the icing/de-icing cycles. Consequently, the mechanical properties of such surfaces must be taken into account in the further development of anti-icing coatings. Overall, our easy and cheap method to engineer nanostructured superhydrophobic surfaces would be an excellent way to make superhydrophobic coatings for $\mathrm{Al}$ alloy surfaces on a large scale.

\section{Acknowledgements}

This research work has been conducted within the framework of the NSERC/Hydro-Quebec/UQAC Industrial Chair on Atmospheric Icing of Power Network Equipment (CIGELE) and the Canada Research Chair on Atmospheric Icing Engineering of Power Networks (INGIVRE) at Université du Québec à Chicoutimi. The authors would like to thank the CIGELE partners (Hydro-Québec, Hydro One, Réseau Transport d'Électricité (RTE), Alcan Cable, K-Line Insulators, Tyco Electronics, Dual-ADE, and FUQAC) whose financial support made this research possible. The authors also wish to thank Mme. H. Grégoire (CTA-CNRC) for her help with SEM analysis and F. Arianpour (Univ. of Quebec) for her help with some experiments.

\section{References}

Andrews, E. H., Majid, H. A., Lockington, N. A. (1984), Adhesion of ice to a flexible substrate, Journal Materials Science, 19, 73-81.

Arianpour, F., Farzaneh M., Kulinich S. A. (2010), Nanopowder-Doped Silicone Rubber Coatings for AntiIce Applications. Proceedings of the International Conference on Nanotechnology: Fundamentals and applications, Ottawa, Ontario, Canada, August 2010, paper no. 497, 8p.

Arianpour, F., Farzaneh, M., Kulinich, S. A. (2013), Hydrophobic and ice-retarding properties of doped silicone rubber coatings, Applied Surface Science, 265, 546-552.

Crick, C. R., Parkin, I. P., (2010), Preparation and Characterisation of Super-Hydrophobic Surfaces. Chemistry A European Journal 16, 3568-3588.

Croutch, V. K., Hartley, R. A. (1992), Adhesion of ice to coatings and the performance of ice release coatings. J. Coat. Technol. 64, 41-52.

Farzaneh, M. (2008), Ed., Atmospheric Icing of Power Networks, Springer, Berlin, August 2008, 320 p.

Farzaneh, M. (2010), Systems for prediction and monitoring of ice shedding, anti-icing and de-icing for overhead lines, CIGRÉ WG B2.29, CIGRE Publications, Technical Brochure \#438, $100 \mathrm{p}$.

Farhadi, S., Farzaneh M., Kulinich S. A. (2011), Anti-Icing Performance of Superhydrophobic Surfaces, Applied Surface Science, 257, 6264-6269.

Furuta, T., Sakai, M., Isobe, T., Nakajima, A. (2009), Evaporation Behavior of Microliter- and Sub-nanoliterScale Water Droplets on Two Different Fluoroalkylsilane Coatings. Langmuir, 25, 11998.

Frignani, A., Zucchi, F., Trabanelli, G., Grassi V. (2006), Protective Action towards Aluminium Corrosion by Silanes with a Long Aliphatic Chain. Corrosion Science, 48 2258-2273.

Guo, Z., Zhou, F., Hao, J., Liu, W. (2005) Stable Biomimetic super-hydrophobic engineering materials. Journal of the American Chemical Society, 127:15670-15671.

Kulinich, S. A., Farzaneh, M. (2004), Hydrophobic properties of surfaces coated with fluoroalkylsiloxane and alkylsiloxane monolayers. Surface Science 573, 379-390.

Kulinich, S. A., Farzaneh, M. (2005), On wetting behavior of fluorocarbon coatings with various chemical and roughness characteristics. Vacuum 79, 255-264.

Kulinich, S. A., Farzaneh, M. (2009), How wetting hysteresis influences ice adhesion strength on superhydrophobic surfaces. Langmuir 25, 8854-8856.

Kulinich, S. A., Farhadi S., Nose K., and Du X.W. (2011), Superhydrophobic Surfaces: Are They Really IceRepellent?, Langmuir 27, 25-29. 
Menini, R., Farzaneh, M. (2009), Elaboration of $\mathrm{Al}_{2} \mathrm{O}_{3} /$ PTFE icephobic coatings for protecting aluminum surfaces, Surface and Coatings Technology, 203, 1941-1946.

Mingjie, L., Yongmei Z., Jin, Z., Lei, J. (2010), Bioinspired Super-antiwetting Interfaces with Special Liquid-Solid Adhesion, Acc. Chem. Res., 43, 368-377.

Miwa, M., Nakajima, A., Fujishima, A., Hashimoto, K., Watanabe, T. (2000), Effects of the surface roughness on sliding angles of water droplets on superhydrophobic surfaces. Langmuir 16, 5754-5760.

Meuler, A. J., Smith, J. D., Varanasi, K. K., Mabry, J. M., McKinley, G. H., Cohen, R. E. (2010), Relationships between Water Wettability and Ice Adhesion, ACS Applied Materials and Interfaces, 2, 3100-3110

Palomino, L. E. M., Pászti, Z., Aoki, I. V., Melo, H. G. De., (2007), Comparative investigation of the adhesion of $\mathrm{Ce}$ conversion layers and silane layers to a AA 2024-T3 substrate through mechanical and electrochemical tests, Materials Research, 10, 399-406.

Petrenko, V. F., Peng, S. (2003). Reduction of ice adhesion to metal by using self-assembling monolayers (SAMs). Canadian Journal of Physics, 81, 387-393.

Quéré, D. (2005), Non-sticking drops. Reports on Progress in Physics, 68, 2495-2532.

Saito, H., Takai, K., Yamauchi, G. (1997), Water- and icerepellent coatings. Surface Coatings International, 80, 168-171.

Spadaro, C., Dispenza C., Sunseri C. (2008), The influence of the nature of the surface oxide on the adhesive fracture energy of aluminium-bonded joints as measured by Tpeel tests, International Journal of Adhesion \& Adhesives, 28, 211-221.

Shaojun, Y., Pehkonenb, S.O., Bin L., Ting, Y.P., Neoh, K.G., Kang, E.T. (2011), Superhydrophobic fluoropolymermodified copper surface via surface graft polymerisation for corrosion protection, Corrosion Science, 53, 27382747.

Somlo, B., Gupta, V. (2001), A hydrophobic self-assembled monolayer with improved adhesion to aluminum for deicing application. Mechanics of Matter, 33, 471-480.

Sarkar, D. K., Farzaneh, M. (2009), Superhydrophobic coatings with reduced ice adhesion. Journal of Adhesion Science and Technology, 23, 1215-1237.

Yao, X., Chen, Q. W., Xu, L., Li, Q. K., Song, Y. L., Gao, X. F., Quéré, D., Jiang, L. (2010), Bioinspired ribbed nanoneedles with robust superhydrophobicity, Advanced Functional Materials, 20, 656- 662.

Yin, B., Fang, L., Tang, A. Q., Huang, Q. L., Hu, J., Mao, J. H., Bai, G., Bai, H. (2011), Novel strategy in increasing stability and corrosion resistance for super-hydrophobic coating on aluminum alloy surfaces, Applied Surface Science, $258,580-585$. 